\title{
Goodbye, Paley... Hello, Charles!: Marketing a Library Move
}

\section{Sara Wilson}

To cite this article: Sara Wilson (2019) Goodbye, Paley... Hello, Charles!: Marketing a Library Move, Public Services Quarterly, 15:3, 256-262, DOI: 10.1080/15228959.2019.1619496

To link to this article: https://doi.org/10.1080/15228959.2019.1619496

册 Published online: 25 Aug 2019.

Submit your article to this journal ¿ð

Џ Article views: 16

Q View related articles $\sqsubset$

View Crossmark data 


\title{
MARKETING
}

\section{Katy Kelly, Column Editor}

Column description: The PSQ Marketing column features essays about a variety of creative and innovative marketing strategies used to bighlight collections or promote services in all types of libraries. Its purpose is to provide real examples of how libraries are using marketing and outreach techniques in interesting ways. The column offers practical insight from libraries engaged with marketing. In addition to marketing, the column also features essays on successful programs and events that promote the library.

\section{Goodbye, Paley ... Hello, Charles!: Marketing a Library Move}

\author{
SARA WILSON \\ Paley Library, Library Outreach and Communications Administrator, Philadelphia, \\ Pennsylvania, USA
}

How do you prepare a campus for the closure of one main library and the opening of a brand-new building? Temple University Libraries faced this question in 2019. Their marketing team answered the call by creating a campaign that honored their original Paley Library while building excitement for the

(C) Sara Wilson

Comments and suggestions should be sent to the Column Editor: Katy Kelly, Coordinator of Marketing and Engagement, University of Dayton, 300 College Park, Dayton, OH 45469-1360. E-mail: kkelly2@udayton.edu

Address correspondence to Sara Wilson, Paley Library, Library Outreach and Communications Administrator, Philadelphia, Pennsylvania, USA. E-mail: sarawilson@temple.edu 
new Charles Library. As part of this campaign, library staff worked together to create their own "Mean Tweets" video, reading real tweets patrons had posted about Paley over the years. In this column, the team's director reflects on the process and how it changed the tone of their overall campaign.

KEYWORDS library move, construction, Twitter, social media, Temple University

Many academic libraries built in the 1960s and 1970s are facing the need to refresh and update their facilities. Temple University Libraries is one of them. But while other campuses are undergoing renovations or additions, we are fortunate that our administration funded the construction of a brand-new facility. Our new Charles Library is a state-of-the-art building designed by Snøhetta, the architects behind the Bibliotheca Alexandrina and the more recent North Carolina State University Hunt Library. Like Hunt Library, Charles utilizes an Automated Storage and Retrieval System (ASRS) for in-house book storage and features other cutting-edge technology along with Snøhetta's innovative style. Charles replaced our main campus building, Samuel L. Paley Library, which closed this year as we moved collections and staff to the new library.

Charles is a very different building than Paley, and due to the complicated nature of the move we made the decision to close Paley a few months before we would be able to open Charles. As the head of the library's outreach and communications team, it was a daunting but exciting task to prepare our campus and neighboring communities for the closure and move. For my team, the process of communicating and marketing the move meant more than looking forward toward our new building. We also wanted to honor our beloved Paley, which opened in 1966. This idea informed much of our marketing that year and launched the "Goodbye, Paley ... Hello, Charles!" campaign.

\section{FINDING INSPIRATION}

To start, we dug through our digital collections to find photos of Paley throughout the years that we could pair with renderings of Charles. We loved one photo in particular, depicting boxes of books stacked outside of Paley waiting to be brought in and shelved for the opening. That image became the cornerstone of our digital and print materials promoting the move. We created posters, postcards, and decals that we distributed around the library and around campus. We also created digital signage, highlighted the move on our 
website, and used the photos on social media. On "Throwback Thursdays" we shared photos from the 1960s and 1970s; for "Transformation Tuesdays" we compared those old photos with images of what those spaces looked like today, or renderings of what they would look like in Charles.

We also utilized our popular "Question of the Week" whiteboard as a communication tool. Each week, we put up a new question or prompt such as "How did you spend your spring break?" and "Describe your favorite book but don't mention the title." For the move, we asked "What will you miss most about Paley Library?" and "What are you most excited for in Charles Library?" Our patrons love chiming in on this board, and including it in our move campaign helped us remind students about the details, harness excitement, and gather feedback about what kind of information people did and did not know. Many patrons wrote that they would miss being able to browse the stacks, which encouraged us to communicate that Charles would still have browsable stacks.

On the final day Paley was open to the public, we threw a "Say Goodbye to Paley Library" party featuring an exhibit of the photos of Paley and a few renderings of the new library. Patrons and staff created zines about the building and explored the building one last time. We also worked with our campus sustainability and surplus team to sell furniture from the building, one of the many times we collaborated with campus partners to manage or promote the closure and move. To close out our final Paley celebration, our dean led other staff members in a musical performance of music from 1966, the year Paley opened. The "Goodbye, Paley ... . Hello, Charles!" campaign took us into the early days of Charles Library, too: we designed a tote bag with Paley on one side and Charles on the other as a giveaway to launch our first year in Charles.

We used another set of "archives" to dig up memories of Paley, too. We mined social media for tagged photos and posts about the building. Many were sweet: students talked about Paley being a familiar, safe space, and visiting researchers shared findings from our archives. Others were not so sweet, complaining about our lack of outlets, smell, or that a nearby patron spoiled their favorite television show. (My personal favorite? "The chairs in Paley Library were crafted by Satan himself.")

When my team started the process, we only planned on keeping track of the good comments. We added them to a team document and shared the links to our favorites directly with each other. Of course, we couldn't help but send each other the ugly ones, too. As we laughed with each other and shared some of our own minor complaints about the building, we realized that the opportunity to bond over the good and bad of the building was something we should share with our patrons.

Thus, "Mean Tweets: Paley Library Edition" was born. Originally a segment on the Jimmy Kimmel show, "Mean Tweets" features people (usually 
celebrities) reading and responding to mean tweets about themselves. I've seen a number of other organizations_-including the City of Philadelphia, which created a video with Mayor Jim Kenney-follow suit, and it has always seemed to be a lighthearted way to show constituents that you're listening.

\section{MAKING "MEAN TWEETS"}

My first step was to come up with a plan we could take to our library dean, Joe Lucia. My team compiled our favorite tweets-filtering out anything that was inappropriate or reflected too poorly on the universityand met with our library tech specialist who agreed to act as our videographer. When we approached Dean Lucia, our idea was to have him read every tweet. He agreed immediately, with the caveat that we get staff from across our organization to read as well. We did a call for volunteers and staff were thrilled to be involved.

Looking back, I'm really glad he made the suggestion to have staff read the tweets and can't imagine the project any other way. The video is better for having a diversity of voices from across the organization, and it was a nice opportunity to highlight library staff that don't have public-facing positions. Many of our staff members have been working in the building for decades and it was just as important for them to say goodbye to the building as it was for our patrons.

Once we had our tweets, our volunteers, and a shooting schedule, we worked with our videographer to create a makeshift studio. We used a step and repeat with our logo as the backdrop and used one of our readers as a test subject. If you attempt a project like this in your own organization, I highly recommend a test subject. We ended up filming her three different times. After the first round, we realized the video highlighted the wrinkles in our step and repeat. For the second round, we used a blank wall for a background. For the third-and final-takes, I brought my personal steamer to work to smooth out the wrinkles in the step and repeat.

To get the footage, we scheduled our readers for 15-minute slots. We asked them to read the tweet a few different times and respond in whichever way felt natural. Some of the staff members really surprised us, showing up in costume or having multiple creative responses prepared. They really embraced the idea, and I think that is clear in the final product. My team worked with our videographer to select our favorite takes, and he edited the video together and added the tweet text to the screen. See Figure 1 for screenshots.

All in all, it took two weeks to bring our Mean Tweets video from concept to launch. When we were ready to go public, we shared it first with library staff. We'd received so much support from our colleagues-who had spent more time in Paley Library than anyone-that we wanted to give 


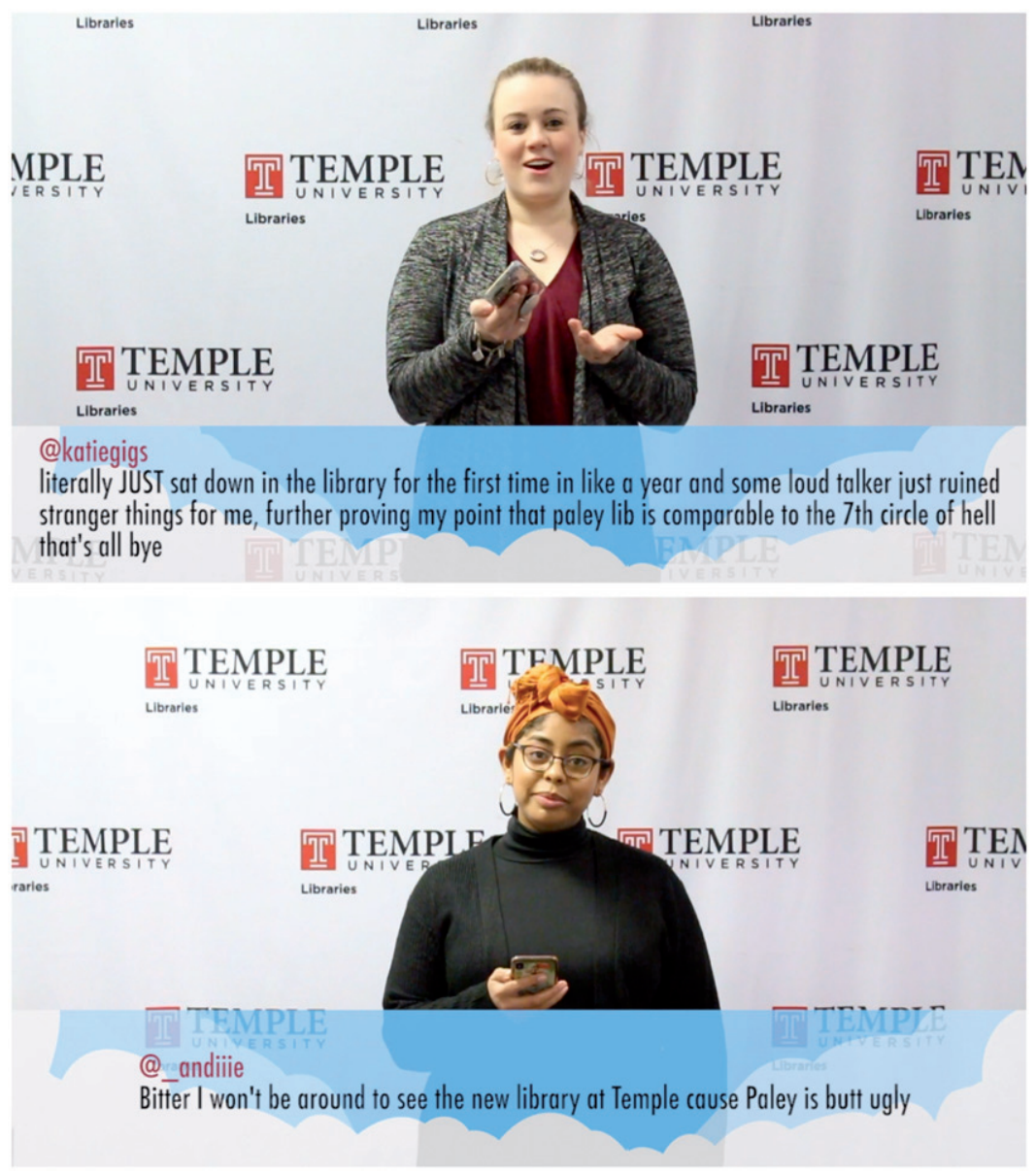

FIGURE 1. Library staff read mean tweets.

them a chance to take first look. Reactions started rolling in quickly. "This is hilarious!" "Coming soon to a theater near me?" "This is the BEST thing I've ever seen! Laughing out loud at my desk. Can this be a weekly thing?"

Not all staff responses were positive. I spent much of that day responding to concerns that the video heightened issues with the building, reflected poorly upon our organization, or could upset library donors. There was also a worry that the organization that was moving into the building after us-and after renovation-would take issue with the video. Although we decided to move forward with making the video public, I took these concerns very seriously and I am glad my colleagues shared them with me. We shared the video with staff first thing in the morning and waited until comments had died down at the end of that day before posting on social media. The positive response from staff far outweighed 
the negative, but we were still nervous to post and huddled as a team around one desk to get the wording for the tweet just right.

\section{THE VERDICT}

It was, overwhelmingly and almost instantly, our most popular tweet. It received over 11,000 impressions, when a very, very good day for us before that was 4 or 5,000. Students and faculty from across the university liked, retweeted, and replied. They shared their favorite memories and tagged each other in the comments. One student thanked us for being there in moments of epiphany and stress. A senior said he hadn't stepped foot inside our building his entire four years of college, but the video inspired him to visit. A few friends reminisced about booking a study room freshman year to do the saltine challenge (collaboration takes many forms, though we don't personally endorse this study method).

And then, just as quickly, it was no longer our most popular tweet. The next day, we posted construction photos of Charles Library like we had done many times before, and our impressions skyrocketed. It made sense: engagement leads to more engagement. But it also felt significant on another levelbonding over our shared love for one building led to excitement for the other.

\section{LOOKING FORWARD}

"Mean Tweets: Paley Library Edition" inspired a few other video projects in the "Goodbye, Paley .... Hello, Charles!" campaign. In our final days in Paley Library (which closed May 9, 2019) our videographer filmed a walkthrough of the building, from students studying for finals in our public spaces to staff working in behind-the-scenes areas. We also converted a study carrel into a video booth patrons could step into on their own to say goodbye to the building or share their favorite memories. We did these projects for archival purposes and for social media content while we are closed over the summer. But we see other uses for them, too. Reviewing the videos helps us focus in on how students make use of the library and what things we did right to contribute to their good experiences and happy memories. Knowing this, we can work to replicate the best parts of Paley Library in our new Charles Library.

In addition to paving the way for other video work, the project marked a shift in our communications about the move. Until then, our approach had been to try to prepare campus for the closure of Paley and the opening of Charles by sharing as much information as possible. This 
meant pushing messaging out through whatever channels we could and monitoring the information that was out there.

The success of "Mean Tweets" significantly lightened the mood around move communications. It encouraged us to do more listening and embrace ways to get feedback. It also reminded us that we wouldn't please everyone and that was okay. The project was also a meaningful way to channel staff anxiety about the move into something productive and positive. We have over 160 staff members at Temple University Libraries, and it is rare to collaborate on a fun, library-wide project with a clear outcome. And, as one staff member said, "it shows that we can laugh about ourselves, and that we are kind of cool."

Stay tuned for "Mean Tweets: Charles Library Edition."

You can watch "Mean Tweets: Paley Library Edition" at https:// tinyurl.com/paleymeantweets 